\title{
The Bubble Eye Sign: Understanding the Radiological Imaging of Gas inside the Orbit
}

\author{
Sunny C. L. Au ${ }^{1, \odot ~ C a l l i e ~ K . ~ L . ~ K o ~}{ }^{1}$ \\ ${ }^{1}$ Department of Ophthalmology, Memorial Ophthalmic Centre, \\ Tung Wah Eastern Hospital, Hong Kong
}

\begin{abstract}
Address for correspondence Sunny C. L. Au, MRCSEd(Ophth), AFCOphthHK, Department of Ophthalmology, 9/F, MO office, Lo Ka Chow Memorial Ophthalmic Centre, Tung Wah Eastern Hospital, 19 Eastern Hospital Road, Causeway Bay, Hong Kong, Hong Kong Special Administrative Region, People's Republic of China, (e-mail: kilihcua@gmail.com).
\end{abstract}

\begin{abstract}
Keywords

- computed tomography

- orbital fractures

- vitrectomy

- X-rays

Gas, appears as radiolucent on X-ray, is normally absent in the orbit. However, intraocular surgeries occasionally utilize retained intraocular gas for tamponade effect. Intravitreal gas persists after retinal surgery, being confounded by the scleral shell of the operated eye, outlines the shape of the eyeball, and gives the characteristic bubble appearance on skull X-ray. This is different from orbital emphysema caused by orbital fracture when gas is located outside the globe but confined by the orbit, giving a crescent or concave shape over the superior orbit usually. Falls is common after intraocular retinal surgeries due to change of usual stereopsis, prolonged prone posturing, and other systemic comorbidities. By identifying the "Bubble Eye sign" described, attending physician should alert the presence of intravitreal gas, most commonly iatrogenic. Further ophthalmological history taking and examinations are thus indicated, instead of exposing patients to unnecessary radiation under computed tomography scan for orbital fracture investigation.
\end{abstract}

A 58-year-old lady underwent pars plana vitrectomy with intravitreal gas $\left(14 \% \mathrm{C}_{3} \mathrm{~F}_{8}\right)$ tamponade for retinal detachment repair. She complied with prone posture and surgical wounds were stable postoperatively. Unfortunately, she fell down the stairs at home the day after discharge from hospital, and readmitted for head injury. Investigation by skull $\mathrm{X}$-ray showed radiolucency over the right orbit in bubble configuration ( - Fig. 1). Attending emergency physician further worked up with computed tomography scan to rule out orbital fractures which revealed negative density within the vitreous cavity ( -990 to -400 Hounsfield's unit) with the

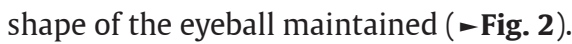

Being a confined space filled by the eyeball and muscles and fat tissue, orbit is free of gas content normally. Without any natural openings, external gas could only enter the orbit via periorbital sinuses, opening of septum either traumatically or surgically; or rarely developed in situ by gas forming anaerobes' infection. Intraocular space is a sterile environment and intraocular gas is sometimes introduced intraoperatively for the intention to retain postoperatively for tamponade purpose. Commonest usage of gas tamponade would be on retinal detachment or macular hole surgery, when long-lasting intraocular gas is utilized as tamponade effect to appose the detached neurosensory retina toward the retinal pigment epithelium, postoperatively. ${ }^{1}$ In addition, gas tamponade is also utilized after posterior lamella keratoplasty for graft apposition to host's corneal stroma. ${ }^{2}$ Depending on the nature of gas, complete resolution varies from days, for air, up to few weeks to months for $\mathrm{SF}_{6}$ or $\mathrm{C}_{3} \mathrm{~F}_{8}$, etc. ${ }^{3}$ published online July 27, 2021
DOI https://doi.org/ $10.1055 / \mathrm{s}-0041-1734359$ ISSN 0971-3026 (c) 2021. Indian Radiological Association.

This is an open access article published by Thieme under the terms of the Creative Commons Attribution-NonDerivative-NonCommercial-License, permitting copying and reproduction so long as the original work is given appropriate credit. Contents may not be used for commercial purposes, or adapted, remixed, transformed or built upon. (https://creativecommons.org/licenses/by-nc-nd/4.0/).

Thieme Medical and Scientific Publishers Private Ltd. A-12, Second Floor, Sector -2, NOIDA -201301, India 


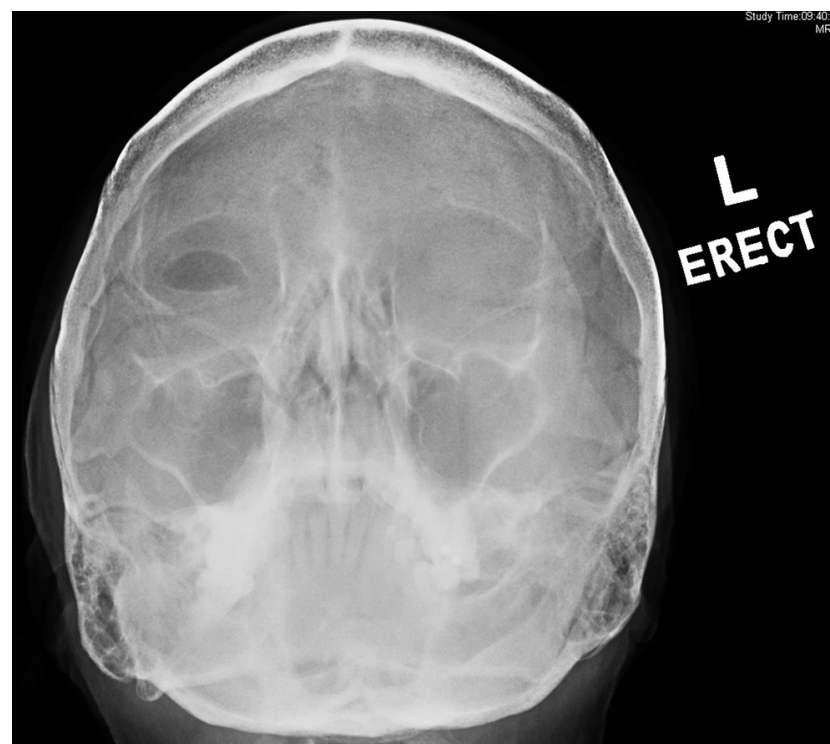

Fig. 1 The bubble eye sign. Orbital X-ray (Waters' view) showing radiolucency over the right orbit. The gas was taking the configuration of a bubble, compatible with gas-filled intravitreal cavity confounded by the eyeball.

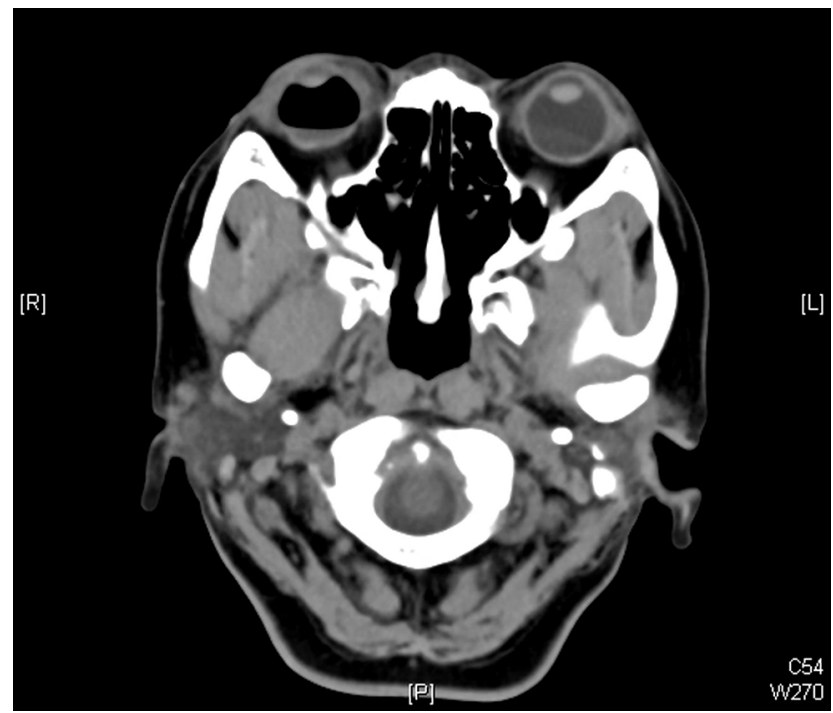

Fig. 2 Computed tomography (transverse cut) of orbit. Right eye intravitreal cavity was filled by radiolucent gas bounded by the scleral shell and the natural lens over this transverse cut.

Volume of intravitreal gas is larger than intracameral gas, and the approximated sphere shaped vitreous cavity allows the intravitreal gas to keep its bubble configuration throughout the whole resorption stages. As gas is radiolucent on radiography, intravitreal gas appears as a radiolucency bubble on X-ray and computed tomography, bounded by the scleral shell, outlining the shape of the eyeball. This "Bubble Eye sign" differentiates intravitreal gas from small orbital emphysema in orbital fracture, when gas is located outside the globe but confined by the orbit, giving a crescent or concave shape usually flowing upwards over the superior orbit (-Figs 3-5).

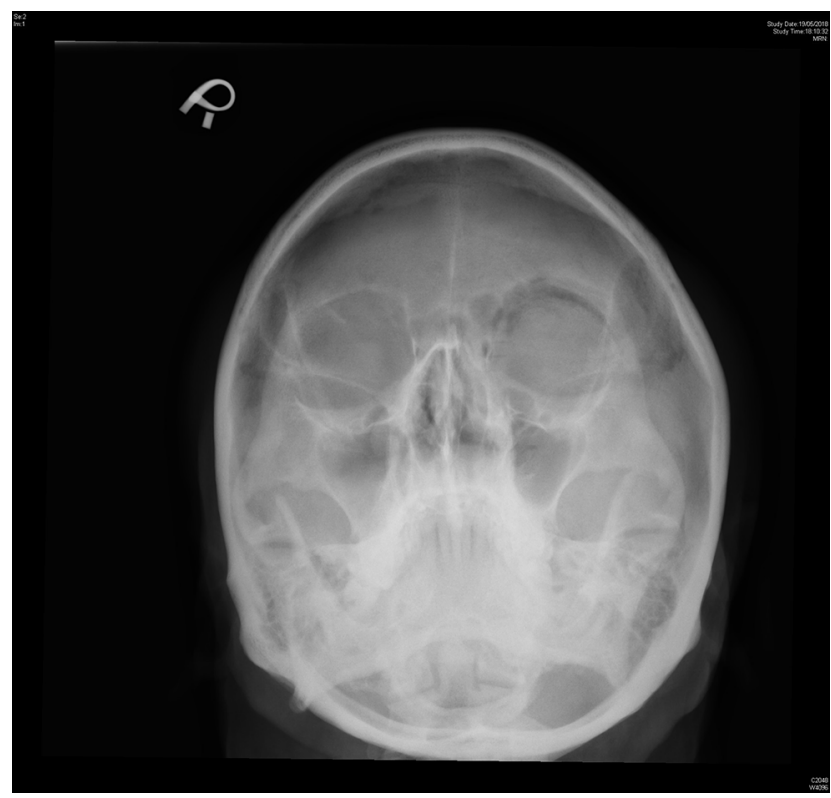

Fig. 3 Orbital X-ray (Waters' view) of another orbital fracture case for comparison. Left orbital emphysema classically seen after orbital fracture was evidenced by the rim of radiolucent gas over the superior orbit. It also outlined the eyeball position, but by its extraocular location.

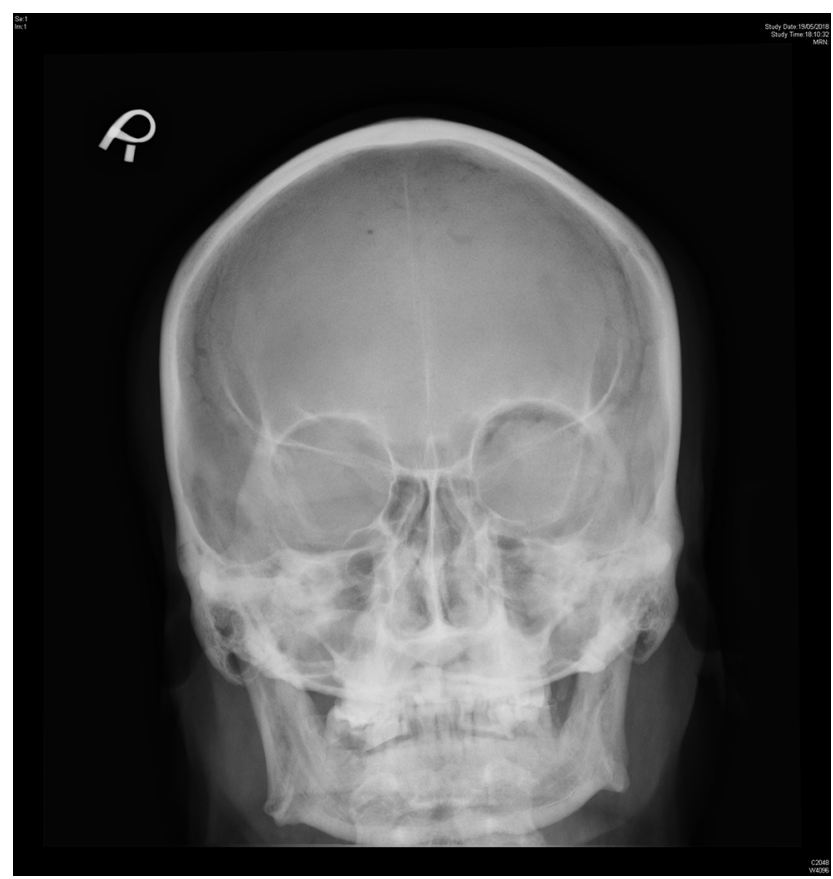

Fig. 4 Orbital X-ray (Caldwell's view) of the same patient in Fig. 3. Discontinuity of the left medial orbital wall suggested the site of orbital fracture.

Traumatic fall is not rare after intraocular surgeries for few reasons. First, there is loss of usual stereopsis. Adaptation to new visual sensation does require time ${ }^{4}$ and a gas-filled eye not only affects visual acuity, but also distorts images by its meniscus level. Second, with prolonged prone posturing after vitreoretinal surgery, patients would feel dizzy on standing and navigating around. Last, in elderly patients with poor 


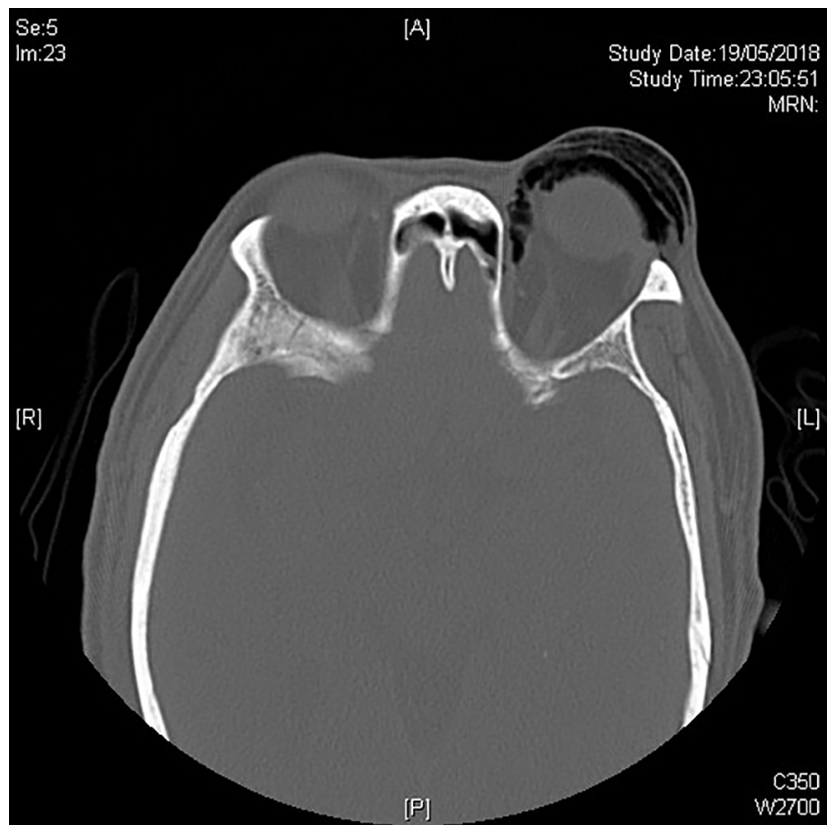

Fig. 5 Computed tomography (transverse cut) of orbit of the same patient in Fig. 3. Left orbital emphysema was well illustrated by the hypodense gas-filled spaces in between the soft tissue planes.

vision over the contralateral eye, their comorbidities, like poor muscle strength, balancing, and gait problems, all contribute to accidental fall even in familiar places. ${ }^{5}$

In conclusion, by identifying the "Bubble Eye sign," physicians can differentiate intravitreal gas from orbital emphysema caused by orbital fracture, when more in-depth ophthalmological history taking and examinations are more indicated than computed tomography scan with radiation exposure to patients.

\section{Declaration of Patient Consent}

The authors certify that they have obtained all appropriate patient consent forms. In the form the patient(s) has/have given his/her/their consent for his/her/their images and other clinical information to be reported in the journal. The patients understand that their names and initials will not be published and due efforts will be made to conceal their identity, but anonymity cannot be guaranteed.

\section{Financial Support and Sponsorship}

None.

\section{Conflicts of Interest}

There are no conflicts of interest.

\section{References}

1 Vaziri K, Schwartz SG, Kishor KS, Flynn HW Jr. Tamponade in the surgical management of retinal detachment. Clin Ophthalmol 2016;10:471-476

2 Singh NP, Said DG, Dua HS. Lamellar keratoplasty techniques. Indian J Ophthalmol 2018;66(9):1239-1250

3 Kontos A, Tee J, Stuart A, Shalchi Z, Williamson TH. Duration of intraocular gases following vitreoretinal surgery. Graefes Arch Clin Exp Ophthalmol 2017;255(2):231-236

4 Ooshiro T, Iijima H. Postoperative recovery of light sensitivity in eyes with rhegmatogenous retinal detachment. Ophthalmologica 2017;238(1,2):52-58

5 Dionyssiotis Y. Analyzing the problem of falls among older people. Int J Gen Med 2012;5:805-813 